\title{
Determination of Thermal Resistances and Optimum Cooling Mode for an Electronic Module used in Electric and Hybrid Vehicles
}

\author{
Sherwin Rajkumara, Sanju Nagendran ${ }^{\mathrm{a}}$, \\ Princeton Benedict ${ }^{\mathrm{a}}$ \\ ${ }^{a}$ Department of Mechanical Engineering, \\ Loyola-ICAM College of Engineering and Technology \\ (LICET), Chennai, India
}

\begin{abstract}
This paper aims at analyzing a double-sided direct liquid cooling system required for a Silicon (Si) based power electronic converter used in electric/hybrid vehicles. The major parameters involved are flow rate of coolant, power dissipated by the die and the temperatures at various points. These parameters are analyzed for various flow rates, various power sources and the simulated results are verified with the superposition theorem. Comparing the thermal resistance for various combinations of flow rates, an optimum cooling mode is proposed.
\end{abstract}

Keywords- Power electronic converter; Cooling system; Electric/hybrid vehicle; Superposition theorem; Direct liquid cooling; Thermal resistance; Double-sided cooling.

\section{INTRODUCTION}

Power Electronic converters are required for converting Alternating Current (AC) to Direct Current (DC) and vice versa in an electric/hybrid vehicle. This means that the power module receives AC from the power socket which should be converted to DC in order to supply it to batteries for charging. In a similar way, the DC power from batteries should be converted to $\mathrm{AC}$ by the converter as the traction motors require an AC supply. During the conversion, conduction and commutation losses in the dies are always present, because of which the conversion efficiency of the converter is never 100\% ${ }^{[1]}$. Consequently, this generates heat in the Power Electronic converter. The flux repartition depends on the temperature gradient between the die and the coolant temperature. This temperature gradient depends on several factors such as mode and type of cooling method chosen, the fluid used for cooling, flow rate of the coolant and power dissipated by the module.

Three types of cooling methods namely single high sided cooling, single low sided cooling and double-sided cooling have been reported to be used ${ }^{[1]}$. In direct liquid cooling method, the coolant is in direct contact with the dissipating surface without an intermediate contact layer. Direct liquid cooling provides promising results as they efficiently carry away the generated heat and so it has been chosen for the study [2]. When forced convection liquid cooling methods are implemented, the power density of the semiconductor package can be greatly improved ${ }^{[3]}$. This paper aims to determine the thermal resistance during the power conversion process.

\author{
James Deepak ${ }^{b}$ \\ ${ }^{\mathrm{b}}$ Assistant Professor, \\ Department of Mechanical Engineering, \\ Loyola-ICAM College of Engineering and Technology \\ (LICET), Chennai, India
}

A cooling system with embedded Si module having four heat dissipating dies in it is chosen for the analysis. The liquid coolant used to carry away this heat is water. The flow rate of coolant is varied for upper and lower flow of double-sided cooling and analysis is done for steady state. The simulation is done for different boundary conditions and the flux repartition results are obtained. In this way the temperatures of the various dies of the power module are calculated for variation in parameters of cooling system and power sources. The outcomes of various conditions are compared, and the optimum flow rate and cooling method is proposed.

In a direct liquid cooling system, no thermal interface is used. By direct liquid cooling method, nearly $30 \%$ reduction in thermal resistance and $40 \%$ reduction in size has been achieved in Insulated-Gate Bipolar Transistors (IGBTs) ${ }^{[4]}$. This proves the efficiency of direct liquid cooling systems.

\section{MODEL DESCRIPTION AND SPECIFICATIONS}

While the major focus in our study is the flux repartition within the power module, a simplified version of the power module was considered. An actual model of the typical power electronic converter could have as much as 31 million elements, which would require a lot of computation time ${ }^{[1]}$ Whereas, the simplified model of the module amounted to around 4.6 million elements which significantly reduced the computing time.

This arrangement consists of a case made of plastic which serves as a passage for coolant flow above and/or below the module. The entire packaging is contained within the case. The package consists of copper spreaders, dielectric gel, silver sintering, dies and bumps. The coolant flows through the passage in this arrangement such that the coolant has direct contact with the spreaders on both the sides.

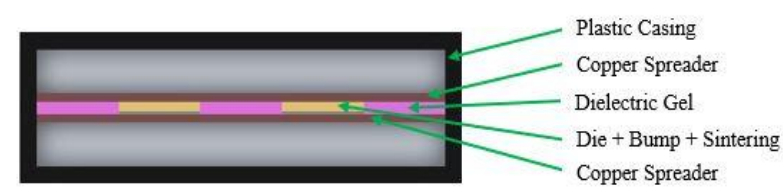

Fig. 1. Entire package cross-section 
The die is sintered using silver to the copper spreader on one side. Sintering is preferred in this case as it can offer better electrical and thermal performance. ${ }^{[5]}$ On the other side, a bump is used as an interconnection between the die and the spreader. The bumps serve the purpose of dissipating the heat in a better way, especially for double sided cooling method. ${ }^{[6]}$

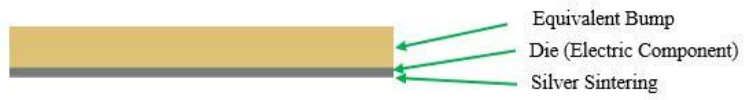

Fig. 2. Die Assembly

The silver sintering makes direct contact with the lower spreader for IGBT 1 and Diode ${ }_{1}$. For IGBT 2 and Diode 2 , the silver sintering makes direct contact with the upper spreader. Depending on the position on the sintering, the bump takes its position on the opposite side. The die, silver sintering and equivalent-bump assemblies are surrounded by dielectric gel to prevent contamination of the electronic components.

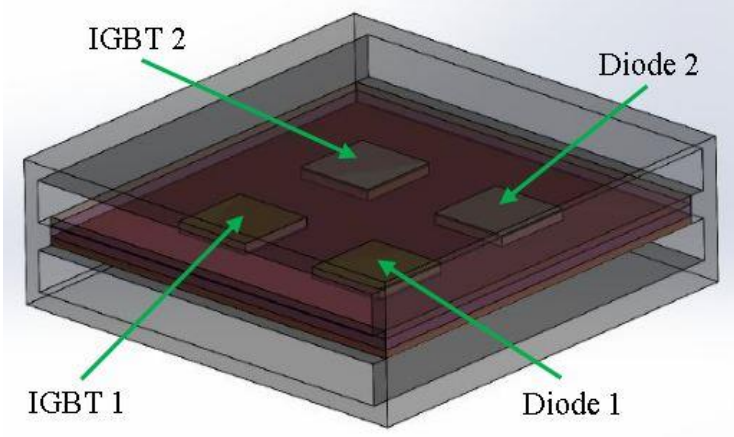

Fig. 3 Power sources

The duct where the coolant flows is plain for its entire length. This makes sure that turbulence is negligible. Hence, a laminar flow has been assumed for the analysis.

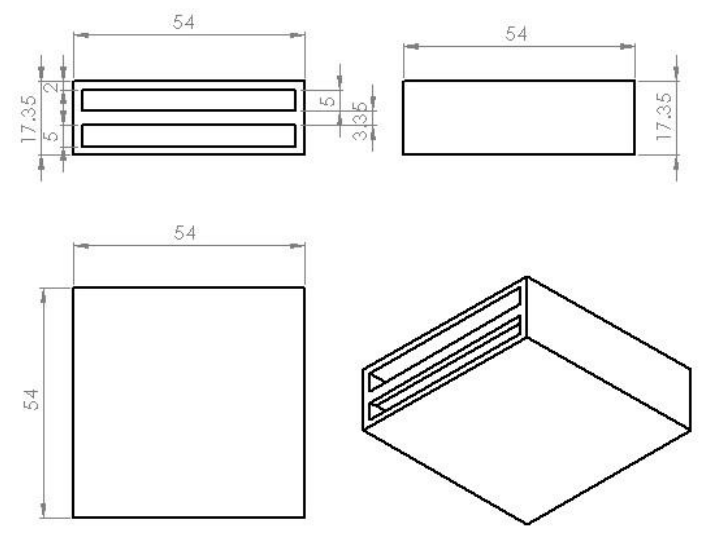

All dimensions are in $\mathrm{mm}$

Fig. 4 Orthographic and isometric views

\begin{tabular}{|l|l|l|l|}
\hline \multicolumn{1}{|c}{ MAterial } & \multicolumn{1}{|c|}{$\begin{array}{c}\text { Density } \\
{\left[\mathrm{kg} / \mathrm{m}^{3}\right]}\end{array}$} & $\begin{array}{c}\text { Conductivity } \\
{[\mathrm{W} / \mathrm{m} . \mathrm{K}]}\end{array}$ & $\begin{array}{c}\text { Specific } \\
\text { heat } \\
{[\mathrm{J} / \mathrm{kg} . \mathrm{K}]}\end{array}$ \\
\hline Copper & 8900 & 390 & 390 \\
\hline Silver sintering & 10500 & 100 & 232 \\
\hline Dielectric gel & 1600 & 0.7 & 3000 \\
\hline Die (Si) & 3000 & 125 & 500 \\
\hline Plastic (ABS) & 1000 & 0.25 & 1005 \\
\hline Equivalent bump & 3888 & 81 & 1104 \\
\hline
\end{tabular}

\section{COMPUTATIONAL MODEL}

\section{A. Initial Setup}

All the simulations were performed using ANSYS Fluent* R2 2019. The void conduits were filled so as to account for the space in which the coolant flows. The topology of the entire model was shared. The three-dimensional model of the whole package was imported as a STEP file under the geometry of the Fluent* Analysis system in workbench*. Firstly, a Multizone meshing method is introduced for all the bodies.

\section{B. Meshing}

The mapped mesh type is set to be Hexahedral and the free mesh type is set to be Hexahedral Core. The mesh sizes are given in the table below.

\section{TABLE II. MESH SIZE OF COMPONENTS}

\begin{tabular}{|c|c|}
\hline Body & Mesh Size $(\mathrm{mm})$ \\
\hline Sintering & $5 \times 10^{-2}$ \\
\hline Dies & $5 \times 10^{-2}$ \\
\hline Case & 5 \\
\hline Fluid Volume & 0.5 \\
\hline Equivalent Bump & $5 \times 10^{-2}$ \\
\hline Spreader and Dielectric Gel & 0.5 \\
\hline
\end{tabular}

As the sintering and die has a lower thickness when compared to the other bodies, a finer mesh has been used for these bodies. The fluid volumes and the region surrounding the die assemblies are also critical in the calculation. So, they have also been assigned with smaller mesh sizes.

* ANSYS Fluent \& Workbench are registered trademarks of US based ANSYS Inc. and its subsidiaries. 


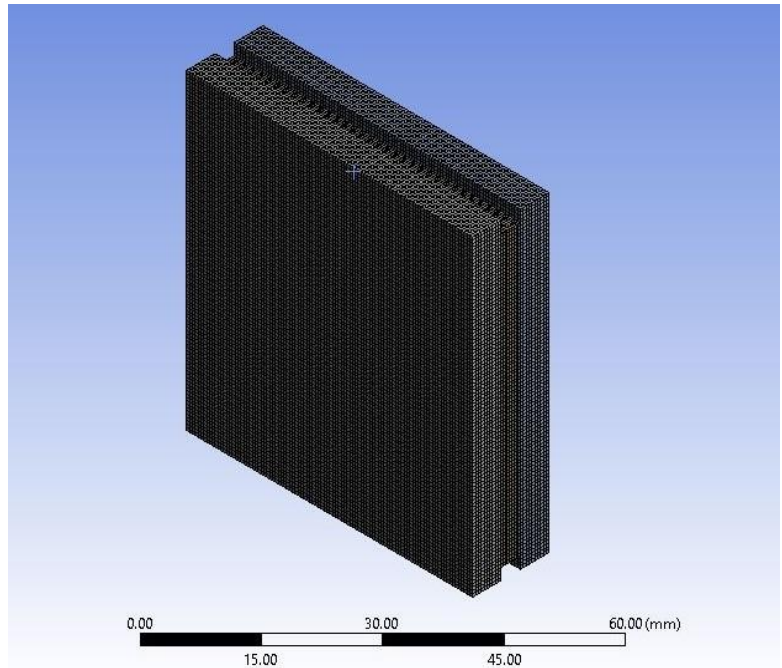

Fig. 5. Isometric view of fluid volumes, spreaders and die assembly

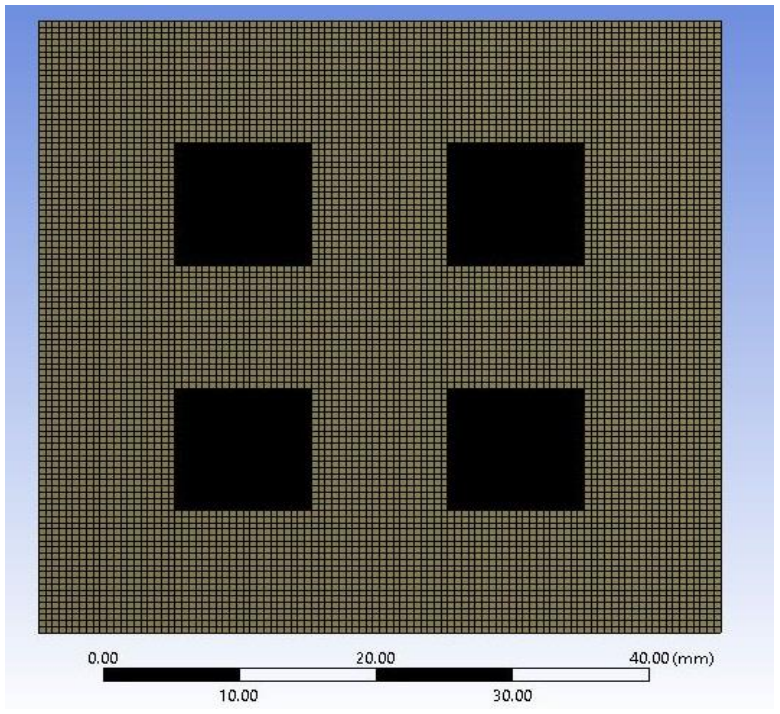

Fig. 6. Top View of the dielectric gel and die assembly

Fig. 5 and Fig. 6 Clearly indicate the differences in the mesh sizes, which is recognized by the darker and lighter portions.

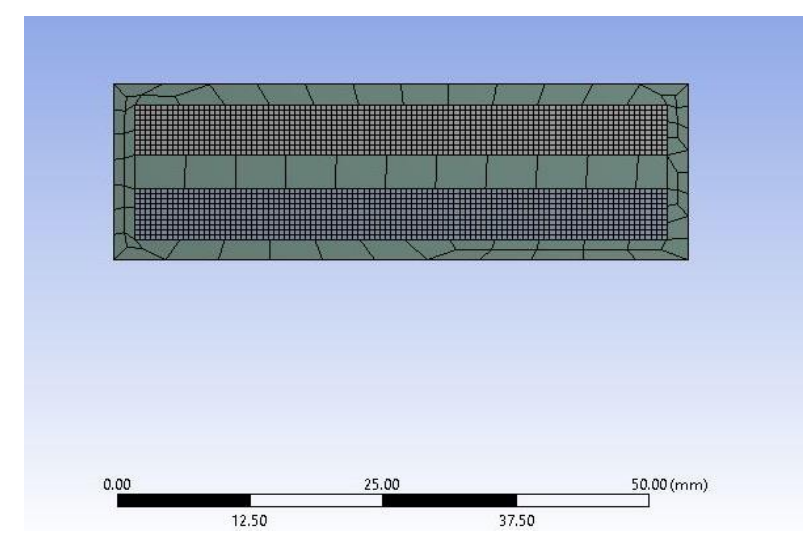

Fig. 7. Front view of the whole package

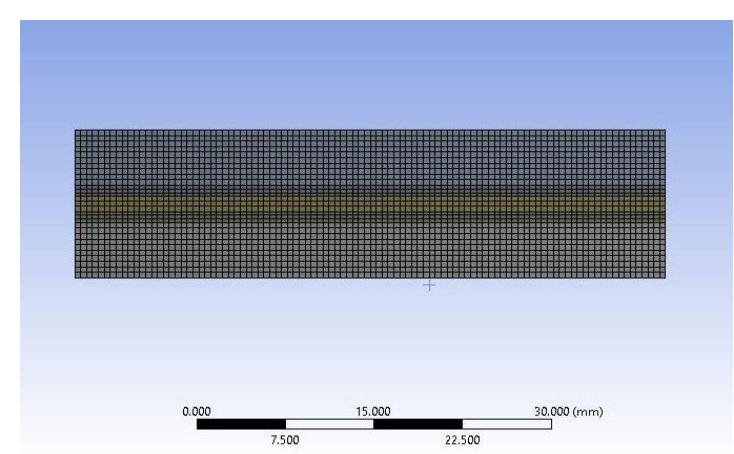

Fig. 8. Front View of the fluid volumes, spreader and die assembly

The model was then imported into Fluent. A steady state, pressure-based solver with absolute velocity formulation was used.

\section{Cell zone and Boundary conditions}

The flow was considered as Laminar and energy equation has been implemented. The various properties considered were density, specific heat and conductivity. Each component was assigned with the corresponding material property. The power dissipated was represented as a heat flux $(100 \mathrm{~W})$ to the corresponding die depending on the case under consideration. The inlets and outlets were mentioned as mass flow type. Firstly, the coolant flow rate was assumed to be 4 lit/min on both the sides of the module. The inlet temperature of the coolant is taken to be $338.15 \mathrm{~K}$ at steady state and the reference temperature is taken to be $293 \mathrm{~K}$, which is the ambient temperature. This model was subjected to five different test cases. In the first case, a power source of $100 \mathrm{~W}$ was given to $\mathrm{IGBT}_{1}$ present at the immediate left of the module when viewed from the fluid inlet face. Similarly, for case 2, case 3, case 4 and load case, corresponding power sources were assigned. Finally, an analysis was made by varying the flow rate of coolant on both sides of the inlets and thermal resistances were calculated. The thermal resistances for various flow rates [(upper, lower)] of the coolant, (01/min, $81 / \mathrm{min}), \quad(21 / \mathrm{min}, 61 / \mathrm{min}), \quad$ (41/min, $41 / \mathrm{min})$, $(61 / \mathrm{min}, 21 / \mathrm{min})$ and $(81 / \mathrm{min}, 01 / \mathrm{min})$ were analyzed for the power dissipation cases 1 and 4 .

The power input to the dies are varied for different cases of analysis as given below.

TABLE III. POWER Distribution For VARIOUS CASES

\begin{tabular}{|l|l|l|l|l|}
\hline & \multicolumn{1}{|c|}{ IGBT $_{\mathbf{1}}$} & \multicolumn{1}{|c|}{ IGBT $_{\mathbf{2}}$} & \multicolumn{1}{|c|}{ Diode $_{\mathbf{1}}$} & \multicolumn{1}{|c|}{ Diode $_{\mathbf{2}}$} \\
\hline Case 1 & 100 & 0 & 0 & 0 \\
\hline Case 2 & 0 & 100 & 0 & 0 \\
\hline Case 3 & 0 & 0 & 100 & 0 \\
\hline Case 4 & 0 & 0 & 0 & 100 \\
\hline Load case & 300 & 300 & 100 & 100 \\
\hline
\end{tabular}

All power values are in Watt 


\section{Post-Processing}

Temperatures of the four dies were extracted from the software using volume-integral technique of calculation. The outlet temperature of the fluid both in the upper and lower passage was found using mass average method. Reference planes were created exactly at the mid-section of each die. The cross-sectional views of the temperature profile of the dies were captured using the contours created using these planes.

\section{IV.RESULTS}

\section{A. Results of simulations}

Simulation was performed for steady state condition for a flow rate of $4 \mathrm{lit} / \mathrm{min}$ on both the ducts. 200 iterations were set initially, and the solution converged at 163rd iteration.
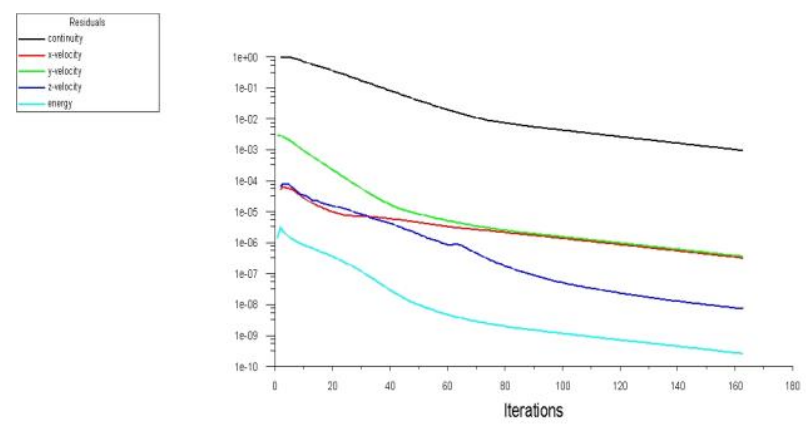

Fig. 9. Residual graph

A temperature profile was obtained at the cross section of the mid portion of the die which dissipates power. This is represented using contours of temperature. The following results indicate the temperature profiles for various cases. (a) Case 1

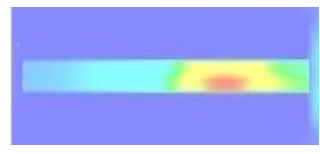

(c) Case 3

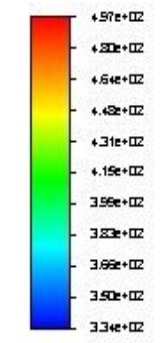

[k]

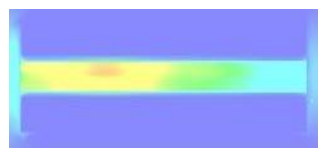

(e) Load case- mid sec 1

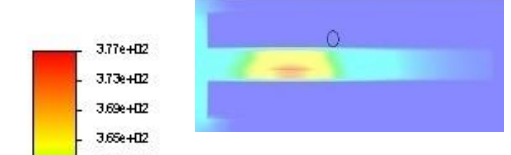

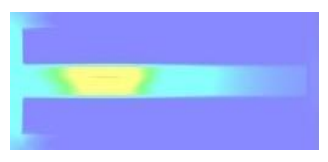

(b) Case 2

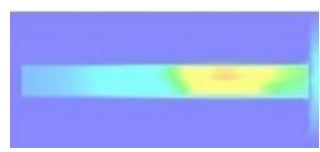

(d) Case 4

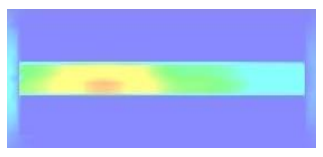

(f) Load case- mid sec 2
Fig. 10 Mid-Section temperature contour
An isometric view displaying the heat zones for the load case, at various positions of the entire module along with the plastic casing is shown.

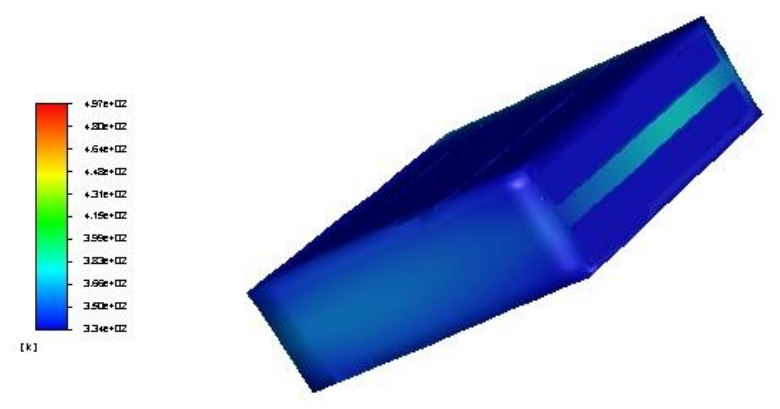

Fig. 11. Overall Temperature Contour

The mean temperatures of the various dies were calculated for each case using volume integral method. The following table gives the temperatures of the various dies for various cases.

TABLE IV. TEMPERATURE ACROSS DIES

\begin{tabular}{|l|l|l|l|l|}
\hline & \multicolumn{1}{|c|}{ IGBT $_{\mathbf{1}}$} & \multicolumn{1}{|c|}{ IGBT $_{\mathbf{2}}$} & \multicolumn{1}{|c|}{ Diode $_{\mathbf{1}}$} & \multicolumn{1}{|c|}{ Diode $_{\mathbf{2}}$} \\
\hline Case 1 & 372.825 & 347.501 & 345.278 & 342.953 \\
\hline Case 2 & 344.815 & 373.18 & 341.51 & 345.54 \\
\hline Case 3 & 345.278 & 342.954 & 372.832 & 347.507 \\
\hline Case 4 & 341.51 & 345.541 & 344.819 & 373.187 \\
\hline Load case & 473.759 & 484.751 & 412.057 & 420.316 \\
\hline
\end{tabular}

All temperatures are in Kelvin.

\section{B. Superposition theorem}

The difference between the temperature at $\mathrm{IGBT}_{1}$ and inlet temperature of water for case 1 is represented by $\Delta T_{j}{ }^{(1)}$ and for case 2 it is represented by $\Delta T_{j_{1}}{ }^{(2)}$ respectively. Similarly, for $\mathrm{IGBT}_{2}$, it is $\Delta T j_{2}{ }^{(1)}, \Delta T j_{2}{ }^{(2)}$ and so on. $P$ is the power given to the dies during the load case while $P_{1}, P_{2}, P_{3}, P_{4}$ are the powers given to $\mathrm{IGBT}_{1}, \mathrm{IGBT}_{2}$, diode 1 and diode 2 respectively during cases $1,2,3$ and 4 . The general formula for superposition theorem is given as

$$
\begin{aligned}
& \Delta T j_{1} \quad=\left(P / P_{I}^{(1)}\right) \mathrm{x} \Delta T j_{1}^{(1)} \quad+\left(P / P_{2}^{(2)}\right) \mathrm{x} \Delta T j_{1}^{(2)} \quad+\quad \ldots \\
& +\left(P / P_{n}^{(n)}\right) \mathrm{x} \Delta T j_{I}{ }^{(n)} \\
& \Delta T_{2}=\left(P / P_{1}{ }^{(1)}\right) \mathrm{x} \Delta T_{j_{2}}{ }^{(1)}+\left(P / P_{2}{ }^{(2)}\right) \quad \mathrm{x} \Delta T_{j_{2}}{ }^{(2)} \quad+\quad \ldots \\
& +\left(P / P_{n}{ }^{(n)}\right) \mathrm{x} \Delta T j_{2}{ }^{(n)} \\
& \Delta T_{n} \quad=\left(P / P_{1}{ }^{(1)}\right) \mathrm{x} \Delta T j_{n}{ }^{(1)} \quad+\left(P / P_{2}^{(2)}\right) \mathrm{x} \Delta T j_{n}{ }^{(2)} \quad+\quad \ldots
\end{aligned}
$$

In the load case, the power given to the IGBTs is $300 \mathrm{~W}$ and for diodes it is $100 \mathrm{~W}$, the above formula is modified for the $\mathrm{IGBT}_{1}$ as

$\triangle T_{j_{1}}\left(I G B T_{1^{-}}\right.$load case by superposition theorem $)=$ $(300 / 100) \times \Delta T j\left(1, I G B T_{1}\right)+(300 / 100) \times \Delta T j\left(2, I G B T_{1}\right)+$ $(100 / 100) \times \Delta T j\left(3, I G B T_{1}\right)+(100 / 100) \times \Delta T j\left(4, I G B T_{1}\right)$ 
Temperature difference for $\mathrm{IGBT}_{1}$ for superposition theorem was found using eqn. (1). Similar modifications were made to the formula for the other IGBT and the two diodes and calculations were made to find $\Delta T_{j}, \Delta T_{j}, \Delta T_{j}, \Delta T_{j}$. Applying the inlet temperature of the coolant $(338.15 \mathrm{~K})$ and temperatures of the dies obtained for the four cases in the superposition theorem, results were compared with the temperatures of the load case.

TABLE V. VERIFICATION OF SUPERPOSITION THEOREM

\begin{tabular}{|l|l|l|}
\hline & \multicolumn{1}{|c|}{$\begin{array}{c}\text { Formulae results } \\
\text { (Temperature difference) }\end{array}$} & \multicolumn{1}{|c|}{$\begin{array}{c}\text { Load case results } \\
\text { (Temperature difference) }\end{array}$} \\
\hline$\Delta T j_{1}$ & 134.508 & 135.609 \\
\hline$\Delta T j_{2}$ & 145.338 & 146.601 \\
\hline$\Delta T j_{3}$ & 72.815 & 73.907 \\
\hline$\Delta T j_{4}$ & 80.973 & 82.166 \\
\hline
\end{tabular}

Although the entire module is symmetrical on all sides, a significant difference between $\Delta T_{j_{1}}$ and $\Delta T j_{2}$ and between $\Delta T j_{3}$ and $\Delta \operatorname{Tj}_{4}$ (Which represents the temperature difference between the inlet and $\mathrm{IGBT}_{1}, \mathrm{IGBT}_{2}$, Diode ${ }_{1}$ and Diode ${ }_{2}$ respectively) can be observed. This could be attributed to the position of the IGBTs and the diodes with respect to the distance from the coolant inlets. As, $\mathrm{IGBT}_{1}$ is positioned nearer to the inlets than $\mathrm{IGBT}_{2}$, the coolant passes over $\mathrm{IGBT}_{1}$ first. This leads to a slight increase in the coolant temperature before it reaches the spreader area over $\mathrm{IGBT}_{2}$. Therefore, $\mathrm{IGBT}_{1}$ is at a lower temperature compared to $\mathrm{IGBT}_{2}$.

\section{Determination of optimum flow rates}

For equal cumulative flow rates of coolant, by varying the flow rates of the upper and lower inlets, thermal resistances were obtained and plotted for two power dissipation cases (Case 1 \& Case 4)

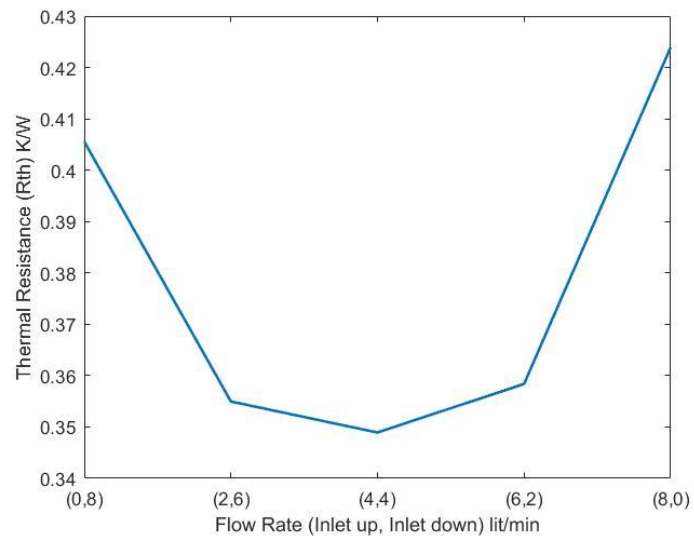

Fig.12. Flow Rate vs Thermal Resistance for Case 1

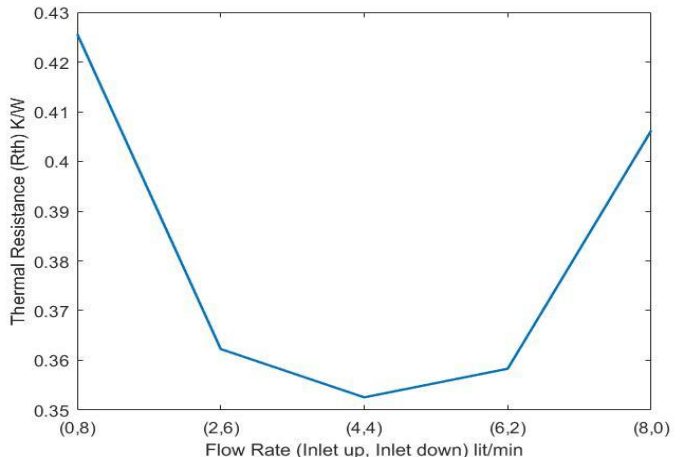

Fig.13. Flow Rate vs Thermal Resistance for Case 4

In both the cases, the thermal resistance has the least value when equal flow rate of the coolant is used on the high side and low side of the dies. In case 1, there is a difference between the thermal resistance values when the flow rate is (21/min, $61 / \mathrm{min})$ and $(61 / \mathrm{min}, 21 / \mathrm{min})$ respectively. In this case the die is sintered to the spreader close to the low side. Thermal resistance has a lower value when the flow rate is (21/min, $61 / \mathrm{min})$. This is because, more heat is dissipated on the lower side than on the higher side for Case 1. So, increasing the flow rate on this side causes better heat transfer. The same phenomenon applies to all the other cases.

\section{CONCLUSIONS}

Temperatures calculated using superposition theorem and the temperatures obtained from various diodes of the load case were compared. The results had a maximum deviation of $1.6 \%$. Hence, the superposition theorem was verified. Furthermore, for the same coolant flow rate, the thermal resistance is found to be minimum when there is an equal coolant flow rate on both of the ducts. The thermal resistance decreases by around $17.3 \%$ in double sided cooling when compared with single sided cooling. This proves the efficiency of double-sided cooling technique. This concept can be extended to find the transient response of the impedances.

\section{REFERENCES}

[1] Sanchez, Sébastien \& Nguyen, C. \& Cadile, Claudia \& Fradin, JeanPierre \& Tounsi, Patrick \& Reynes, Jean-Michel. (2020) Electrothermal Characterization of Double-Sided Cooling Si Power Module. 10.1007/978-3-030-37161-6_5.

[2] M. Schneider-Ramelow, T. Baumann and E. Hoene, "Design and assembly of power semiconductors with double-sided water cooling," 5th International Conference on Integrated Power Electronics Systems, Nuremberg, Germany, 2008, pp. 1-7.

[3] B. C. Charboneau et al., "Double-Sided Liquid Cooling for Power Semiconductor Devices Using Embedded Power Packaging," in IEEE Transactions on Industry Applications, vol. 44, no. 5, pp. 1645-1655, Sept.-Oct. 2008.

[4] Hitachi, T. \& Hiromichi, G. \& Nagaune, F.. (2012). Direct liquid cooling IGBT module for automotive applications. Fuji Electric Rev. 58. 55-59.

[5] C. Buttay, B. Allard and R. Riva, "Silver sintering for power electronics integration," 2015 International Conference on Electronics Packaging and iMAPS All Asia Conference (ICEPIAAC), Kyoto, 2015, pp. 554-558, doi: 10.1109/ICEPIAAC.2015.7111076.

[6] Chia-Chi Tsai, Li-Ling Liao, Yen-Fu Su, T. Hung and K. Chiang, "Reliability analysis of copper bump interconnection in doublesided power module," 2015 16th International Conference on Thermal, Mechanical and Multi-Physics Simulation and Experiments in Microelectronics and Microsystems, Budapest, 2015, pp. 1-4, doi: 10.1109/EuroSimE.2015.7103093. 